\section{Bestimmungslisten für Medikamente}

C. Vidal ${ }^{1}$ und W.-R. Külpmann ${ }^{2}$

${ }^{1}$ Landeskriminalamt Niedersachsen, Dezernat 53 „Chemie“, Hannover, Deutschland

${ }^{2}$ Hannover, Deutschland

Englischer Begriff pill identification list
Beschreibung Werden bei einem Patienten Medikamente gefunden (z. B. lose Tabletten, Dragees etc.), kann häufig anhand von Pharmazeutika-Bestimmungslisten eine Identifikation vorgenommen werden.

\section{Literatur}

Pharmazeutika Bestimmungsliste. IMP Verlagsges, Neu-Isenburg Heinisch G, Gerold W (1987) Arzneimittel-Schnellerkennung. Österr, Apotheker-Verlagsgesellschaft 